This is an accepted manuscript of an article published by Taylor \& Francis group in Teaching in Higher Education on 23/09/2013, available online: http://www.tandfonline.com/doi/abs/10.1080/13562517.2014.957270

Para citar:

Gallego-Arrufat, M.J. \& Gutiérrez-Santiuste, E. (2015). Perception of democracy in computer-mediated communication: Participation, responsibility, collaboration, and reflection. Teaching in Higher Education, 20(1), 92-106. doi:10.1080/13562517.2014.957270

\title{
Perception of democracy in computer-mediated communication: participation, responsibility, collaboration, and reflection
}

\begin{abstract}
We present a case study, the goal of which is to observe how students in Higher Education $(\mathrm{N}=100)$ democratize the virtual classroom by assuming responsibility for their learning and that of the other members of the class; participate actively in social, cognitive, and teaching issues; and collaborate by creating a learning community and reflecting individually and as a group. We use a mixed methodology including: (a) content analysis with a categorization system adapted from the Community of Inquiry (CoI) approach and (b) two questionnaires for observing students' perception of the democratic elements in the virtual classroom. The results show that the students assume democratic principles of responsibility, critique, participation, and collaboration. We observe the role that the professors play in facilitating democratization of the classroom through flexible design of instruction, promotion of social relationships, and direction of the debate toward the learning objectives.
\end{abstract}

Keywords: computer-mediated communication, community of inquiry, academic democracy, student participation, higher education

\section{Introduction}

True democracy is a fundamental value in Western societies, and all systems established in these societies must have their foundations in participatory, responsible and critical 
social models. The history of the democratic project is to a great extent the history of struggles for the inclusion of the social groups and subgroups excluded from participation (Grossman 2008). In the classroom, a fundamental democratic value is giving voice to the members who participate in the teaching-learning process. As Bennett, Wells \& Rank (2009) argue, democratic education requires greater participation in the definition of problems, production of information, and construction of action.

As a complex, dynamic system, distance education (Daniels 2012) consists of the interrelation of many subsystems-social systems, education systems, and teaching/learning systems - (Saba 2003) and must be grounded in democratic ideals.

The student is the central focus of the educational activity. Virtual education must also reflect this fact, stimulating the provision of student learning environments in which communication and interaction are the architects of learning performed as a community.

Our research questions are:

- Do students in a virtual environment perceive democratic principles at work through participation, responsibility, collaboration, and reflection?

- How do students perceive the role of professors who facilitate democratization of the virtual classroom?

\section{Democratic values in the virtual classroom}

Democracy and debate involve a process of giving and receiving, speaking and listening, describing and bearing witness to our democratic principles, enabling collective wisdom that would be impossible to achieve by any participant independently (Brookfield \& Preskill 2005). Social interaction plays a crucial role in the learning 
process, making the design of tasks that provide occasions for collaboration with adequate support to promote, organize, and coordinate participation an important pedagogical objective. Professors and students should exercise principles of academic democracy. Technological advance has opened our possibilities for breaking with hierarchical pedagogical structures. Actions are now based on active participation that enriches the teaching-learning process. Garrison \& Anderson (2003) argue that the use of computer-mediated communication (CMC) in education has a liberating, transformative effect and enables new educational focuses, since it expands the possibilities for interaction.

For Garrison \& Baynton (1987), the concept of interaction consists of three components: independence (the degree to which the students are free to do things), power (the ability and competence of students who participate in the learning experience), and support (the resources available to enable students to participate satisfactorily). Thus, in the transactional view of education and learning outlined by Garrison \& Archer (2000), students' control is related to assuming responsibility for their learning, since the key factor is found in the possibility of choice.

Active participation means that students cease to have the role of mere receiver/consumer of information and adopt a position on the order of co-constructor and committed citizen in the educational environment. This transformation requires that participants be involved in the dynamic of creation and dissemination of knowledge.

As Mainkar (2008) indicates, there are two basic criteria for measuring participation in discussion: quantity and quality. The quantity of interaction can be determined through a relatively easy process. Quality is determined by the content of the communication. In our study, quality is a balance of three elements: social, cognitive, and pedagogical, which constitute the CoI model — social, cognitive, and 
teaching presence (Garrison, Anderson, \& Archer 2000). It reflects dialogic participation in a critical discussion. Manca, Delfino, \& Mazzoni (2008) believe that analyses based on references give us more information than analyses based on technological data and, most importantly, provide us with more precise information on the communicative relationships of participants.

Garrison, Anderson, \& Archer (2003), on the other hand, find that the written word can both foster reflection through contributions to discussion, making them more complex, and develop in more advanced stages of critical thinking. Participation, responsibility, collaboration, and reflection in virtual learning environments have been researched unevenly. Synchronous communication has received less analysis (Burnett 2003) and presents a higher level of interaction than asynchronous (Hrastinski, Keller, \& Carlsson 2010). The construction of collectively shared meaning has traditionally been attributed to asynchronous communication (Scardalia 2002), but such coconstruction is also possible through synchronous tools (Stein et al. 2013).

\section{Community of Inquiry: spaces for democratic action}

Within the theoretical framework of the Community of Inquiry (CoI), which Garrison and colleagues have developed for over a decade (Garrison, Anderson, \& Archer 2000), research shows that virtual learning communities are spaces that encourage students to assume and perform communication oriented to achieving democratic principles. The theoretical foundations of the CoI model develop the perspective of learning within a constructive-cooperative framework that recognizes interaction between individual meaning and socially constructed knowledge (Garrison, Anderson, \& Archer 2000). The socio-cultural concepts and results of this research seem to have had relatively slight impact on educational policy and practice to date, both what happens in classrooms and change in the status quo to achieve better educational results (Mercer \& Howe 2012). 


\section{Cognitive presence}

Cognitive presence indicates the extent to which students are able to construct meaning through continuous reflection in a critical research community (Garrison, Anderson, \& Archer 2001) and through sustained communication (Gunawardena, Lowe, \& Anderson 1997; Salmon 2004). Garrison \& Anderson (2003) define it as the intellectual environment that grounds sustained critical discourse, both improving the regulation of cognition and choosing strategies (Garrison \& Akyol 2013). The model identifies four nonsequential phases of cognitive presence: triggering event, exploration, integration, and resolution (Garrison \& Anderson 2003; Kanuka, Rourke, \& Laflamme 2007; Park 2009).

\section{Social presence}

Social presence is the capability of participants to project themselves socially and emotionally as real individuals to stimulate direct communication between people, achieving personal representation (Akyol, Garrison, \& Ozden 2009; Garrison \& Anderson 2003). Remesal \& Colomina (2013) hold that social presence is an interactive, evolving construction among participants that seeks to achieve shared, collaborative learning objectives; it is not a post-hoc individual perception but establishes a clear connection between the creation and maintenance of social presence and the regulation of motivating processes. It is a crucial requirement for cooperation and critical discourse, stimulating the connection with what the other members are thinking (Garrison \& Akyol 2013). Social presence contains the following elements: affective communication, open communication, and cohesion (Garrison \& Anderson 2003; Garrison, Cleveland-Innes, \& Fung 2010; Rourke et al. 1999). 


\section{Teaching presence}

An educational experience requires an encouraging architect to design, direct, and nourish the transaction. This is defined as the action of defining, facilitating, and orienting the cognitive and social processes to the goals of obtaining the expected results according to the students' needs and capabilities (Garrison \& Anderson 2003). In considering the literature, however, we see that this role is changing and expanding in virtual learning environments and becoming that of a mediator and facilitator (Cabero et al. 2008; Laurillard 2002), advisor (Rotta \& Ranieri 2005), moderator (Salmon 2000), or co-researcher (Brubaker 2012).

In this context, the figure of professor has been constructed anew to enable more democratic teaching practices and to train future teachers to teach in a way that reflects more on the needs of their students (Brubaker 2012). This also means that some teaching functions are being distributed among the members of the group, extending the moderating role to the student (Asterhan \& Schwarz 2010). Teaching presence is composed of design and organization, facilitation of discourse, and direct teaching (Anderson et al. 2001; Stenbom, Hrastinski, \& Cleveland-Innes 2012).

\section{Instructional design}

The methodology used in the virtual sessions in this study is a socio-constructivist approach in which professors assume the role of manager, guide, and advisor. The students are co-participants in constructed knowledge, along the lines of the approach developed by Mercer \& Howe (2012) in a b-learning environment.

Two face-to-face sessions were held in which the course objectives, methodology, and synchronous and asynchronous instruments (text-based communications) were explained. The students were to analyze a series of documents 
with educational content (videos, ebooks, blogs, forums, wikis, web pages, and reports) before the chat sessions, which were used as a place to share, discuss, and socialize. The chat sessions took place over seven weeks and lasted 40 minutes each. The forums were used later as a place for reflection, agreement, and summarizing of the ideas worked out together. The forums were open for communication for a period of three months during each academic year.

The professors' task was to clarify the pedagogical focus and create an environment that was fruitful for knowledge construction (Weinberger, Stegmann, \& Fischer 2007). The professors also helped to construct mental models, stimulating cohesion, managing conflict, and initiating activities. We take into account the importance of the different social personalities that each individual adopts depending on the rules and context in which the communication developed (Tajfel 1974). Therefore, from the start of the educational relationship, we presented how the sessions would develop: through discussion, contrast of ideas, collaboration, and co-construction.

\section{Methodology}

The research was performed with content analysis of the online communications over the course of two academic years. The sample consists of 98 advanced undergraduate students in the Education Sciences and two professors. The students' ages ranged from 19 to 38 years old, with a mode of 21 . The distribution by gender was $88.35 \%$ women and $11.65 \%$ men. We used the thematic unit as a unit of analysis (Aviv et al. 2003).

The synchronous communications consist of a total of 63 chats $(10,363$ thematic units). The asynchronous communications include two forums (1924 thematic units).

The categorization system for the virtual communications was established using the approach of Garrison \& Anderson (2003), modified in the light of other research (Akayoğlu, Altun, \& Stevens 2009; Garrison, Cleveland-Innes, \& Fung 2004; Garrison 
et al. 2006; Park 2009; Perera 2007) and of the findings in the process of codifying the data itself (see Appendix).

We also created two questionnaires (on the chat and the forum) to obtain information about the students' perception of the democratic elements in the virtual classroom. The scale is a Likert-type scale with four levels ( $1=\mathrm{I}$ disagree completely with the statement /Absolutely not; 4=I agree completely with the statement /A lot). The 22 items refer to three issues: (a) democratic aspects of the virtual communicationparticipation, responsibility, collaboration, and reflection; (b) opinion about the professors' actions - promotion of the debate, support, and monitoring of the students, facilitation of a good study climate, attitude, incitement to individual responsibility; and (c) general aspects: respectful communication, good impression of the activities, positive personal attitude.

\section{Reliability and validity}

We analyzed concordance in the categorization system to ensure that the categories are defined correctly according to an analysis using intercodifiers. ICC $=.584$ is moderate and acceptable to confirm the categorization system as correct (Landis \& Koch 1977).

To establish the degree of reliability, understood as accuracy in the process of assigning thematic units to the indicators, we performed a double review of the categorization and created a matrix crossing all of the indicators.

The reliability of the questionnaires was determined by the Alpha Cronbach; for the chat questionnaire $(=.719)$ and $=.837$ for the forum questionnaire.

For reliability of the results, we obtain the following using Friedman's F-test:

- Chat. Contrast parameters: ${ }^{2}=33.60, p<0.05$.

Mean rank: Facets $=1.44$, General $=2.29$, Professors $=2.27$ 
- $\quad$ Forum. Contrast parameters: ${ }^{2}=30.37, p<0.05$.

Mean rank: Facets $=2.36$, General $=1.49$, Professors $=2.15$

The questionnaire items were reviewed by eight experts and obtained $79.8 \%$ agreement for the suitability of the items and their proper phrasing.

\section{Results}

We categorized a total of 12,121 thematic units. In analyzing the virtual communications as a whole (chats and forums), we found that $20.05 \%$ of the communications were made by the professors and $79.95 \%$ by the students. In examining the type of presence to which these are assigned, according to the tool used, we establish the findings presented in Figure 1:

Figure 1 near here.

The percentages presented in Figure 1 suggest various issues:

- The students as a group assume responsibility for achieving both the learning objectives, by constructing meaning through reflection, and the inferencesunderstanding, verifying, and organizing the knowledge.

- The students establish strong social relationships in a group made cohesive by their personal projection in the group. The students use direct, affective communications between people, creating a climate of trust and acceptance.

- The students accept responsibilities that refer to the organization and planning of the teaching-learning process but also related to stimulating the members' role as co-constructors of meaning.

- The professors assume essentially two responsibilities: (a) pedagogical aspects of the chat-although they do not do this in the forums, in which their work is 
only that of manager; (b) active participation in establishing group social relations in the chats by promoting cohesion and affective communication and communicating openly with the students.

By examining the number of people who compose each group, we find the distribution of the contributions shown in Table 1:

Table 1 near here.

We see from Table 1 that the distribution of the students' contributions in the forums is higher for cognitive and social topics. The professors' participation is considerably higher in teaching issues. In the chats, we see a much greater contribution from professors in all cases.

\section{Cognitive communication}

Figure 2 shows the distribution in percentages (of the total communications performed with each tool) of the 6,933 thematic units categorized under Cognitive presence.

Figure 2 near here.

The students make more contributions as a group than do the professors, and student contributions are related to the integration of knowledge and the exploration of relevant information in both the forums and the chats. The highest percentages of contributions correspond to issues related to information exchange, integration or summary of previous information, expression of agreement with previous messages, expression of confirmations from one's own experience, direct responses to questions related to the topic of study, proposals for solutions to topics treated, and defense of a position presented. 
The professors' contributions related to cognitive elements involve essentially agreement with previous messages, information exchange, and request for clarifications or expansion on concepts presented previously.

\section{Social communications}

Social presence contains 3956 categorizations, distributed according to subcategories, as shown in Figure 3 (the total number of communications performed in each tool):

Figure 3 near here.

As for the case of cognitive presence, we see a large number of contributions by students. These are related essentially to the three aspects that compose this presence. The first of these is group cohesion: use of vocatives, greetings, and sentences that refer to a we as group, in many cases using inclusive pronouns. This reflects the conception of the group as members both of the virtual learning community and as a group of future professionals. Second are communications relating to affect: thanks (to the professors and the other members for sharing the conversation and acts of collaboration or clarification of questions) and expression of emotions of satisfaction, confusion, or the person's own personality. Third, we find communications related to open communication: response to questions not related to the study topic.

Although the percentage is far smaller, the professors have contributed virtual communications related to cohesion: use of vocatives, greetings, and sentences that promote the inclusion of members of the group, especially in the chats. We can see in the forums, however, that social communications are far fewer in number and focus only on cohesion. 


\section{Pedagogical communications}

Communications of a pedagogical character on the chats and forums (1398 thematic units categorized) are more numerous in the chats and are performed by professors, as can be seen in Figure 4 (especially in the total communications made in this tool). We eliminated categories below $0.5 \%$.

Figure 4 near here.

In the case of the forums, students' contributions relating to the direct instruction are significant, especially the explanation of an idea mentioning the origin or source and summarizing the content of the discussion. We also find communications related to facilitating discourse, essentially comments that draw out participants' opinions to promote debate and issues related to design and organization-primarily comments clarifying and orienting others to the use of the technology tool.

\section{Students'perception}

To contrast and expand the information obtained from the analysis of the virtual communications, we analyzed the students' perception of the democratic atmosphere in the virtual classroom. Table 2 presents the mean and standard deviation of the items.

Table 2 near here.

The students have a strong perception of the presence of democratic issues in the virtual communication, as well as a positive perception of the professors' actions. They also recognize communications based on respect, maintaining a positive attitude. This gives the students a very positive impression of the activities developed virtually. All of the elements analyzed have a very low standard deviation. 
We examined the linear correlations through the Pearson's correlation coefficient and find the correlation coefficient between positive attitude of the students and participation, responsibility, and reflection to be high and positive (0.6-0.8) (Bisquerra 1989) ( Sg.<.01, 2-tailed). We also find this level of correlation between the good impression of the course and participation. In the other cases, the correlations are moderate and positive (0.4-0.6) (Bisquerra 1989). We also find moderate and positive correlations between the students' perception of the professors' behavior and aspects of democratic communication.

\section{Conclusions and discussion}

The virtual communications demonstrate the members' involvement in a learning community in a technological environment. In light of the findings, we believe that the democratic support for participation, responsibility, collaboration, and reflection appear in virtual classrooms. Students perceive these aspects, and they are found widely in the students' synchronous and asynchronous communications. The professors organized and planned activities in a way that made it possible to give the students' voice without abandoning the role of advisor, mediator, and facilitator. Hierarchical structures were abandoned, giving way to greater communicative force of students, who were not mere consumers of information but co-constructors of shared knowledge. The students grasped the liberating and transformative effect of the interactions in which the professors assumed their responsibility in a way complementary to that of the students. Active participation, responsibility, collaboration, and reflection in the individual and the group stimulated students to have a very favorable impression of the virtual activities developed through respect and a positive attitude. 
The democratic issues analyzed are seen in all of the kinds of virtual communication: communications that focus on the learning objectives, on social relations, and on pedagogical aspects of the computer-mediated communication situation.

Although other studies find differences in the characteristics of the communications (Oliveira, Tinoca, \& Pereira 2011), the students explore and integrate knowledge by constructing meaning and reflecting continuously using the two tools analyzed. The virtual contents are constituted by understanding the nature of the problems and providing possible explanations on a divergent plane of thought. The students achieve high levels of problem-solving by confirming and defending their positions. They have taken responsibility for the learning objectives and active participation in the debates.

As for the professors, we found cognitive expressions only in the chats (as in the study by Burnett 2003). The professors made a considerably smaller number of communications, which focused on issues of acceptance and agreement with students' messages, information exchange, and request for clarification. The students assumed and took responsibility for the cognitive objectives, due possibly to their high cognitive aspirations and the lack of cognitive communication from the professors. Our data agree with those of Carr et al. (2004), whose findings show that students take responsibility for argumentation in the absence of a professor.

Our study finds a high level of social relations through self-expression as a real person in the virtual community and recognition of the other members as integral parts of this community. Communications related to the group's cohesion fostered the group dynamic and high degrees of interaction. An environment of collaborative learning and 
shared motivation was obtained. We found many communications about the inclusion of members, facilitating the maintenance of commitment.

Demonstrations of affect related to greetings, vocatives, and gratitude are considerably higher in the chats. They establish a close, cordial relationship between students, in a way similar to that found in the study by Traphagan et al. (2010). This result may be due to the fact that the chat sessions were held first and then the communications through forums.

The professors recognized the role of the community as stimulating to the construction of meaning and the promotion of mutual understanding. They also noticed contributions concerned with adaptation to changes during the educational transaction and flexibility in course design justified by the cooperative and constructivist conception of the relationship. The professors guided virtual communications that centered the debate on the learning objectives. Our study thus agrees with that by Nagel \& Kotzé (2010) in observing that professors play a fundamental role in the constructing and organizing the educational process by supporting both cognitive and social aspects. We also wish to stress that the students contributed information, based on sources that demonstrate their involvement in and responsibility for advancing joint production of knowledge.

The CoI model presupposes that teaching presence is assumed by the professors (Anderson et al. 2001) as architects and encouragers of the educational transaction, and the data shown in Table 1 show this to be the case, a result that agrees with the study by Stein et al. (2013). In our study, however, we also see how aspects of injecting knowledge and summarizing are assumed by the students. Whereas the professors focus their communication on facilitating discourse and on design and organization, the students focus on relating to aspects of direct instruction. 
Our study agrees with that performed by Hrastinski, Keller, \& Carlsson (2010), since the synchronous communication shows more interaction than the asynchronous. The two modalities complement each other, synchronous for supporting participation, motivation, and convergence with messages (Hrastinski 2008). Along similar lines, the study by Chou (2002) finds that synchronous communication produces more opportunities for interpersonal relation and information exchange. Remesal \& Colomina (2013) indicate that it is advisable to balance the different facets of social presence, although our study did not observe this weighting.

Our study does not find contributions related to inspiring confidence and collective identity (Oliveira, Tinoca, \& Pereira 2011) through negotiation and social presence. The students had read and reflected on the tasks before the chat sessions-as the professors had requested-making possible a significant advance in the explanation, active participation, and co-construction of joint meanings (Oliveira, Tinoca, \& Pereira 2011). There is a clear intent to discuss the different points of view and to harmonize the participation, which demonstrates an acceptance of the power granted to the students as well as democratic practice in the classroom.

The students perceived academic democracy, and the members of the learning community (professors and students) practiced it through participation, responsibility, collaboration, and reflection.

We should, however, consider the study's limitation involving the domain of the technology tools used, since this may have been a factor influencing the greater or lesser degree and type of use. 


\section{References}

Akayoğlu, Sedat, Arif Altun, \& Vance Stevens. 2009. «Social presence in synchronous text-based computer-mediated communication». Eurasian Journal of Educational Research (34): 1-16.

Akyol, Zehra, D. Randy Garrison, \& M. Yasar Ozden. 2009. «Online and blended communities of inquiry: Exploring the developmental and perceptional differences». International Review of Research in Open \& Distance Learning 10 (6): $65-83$.

Anderson, Terry, Liam Rourke, D. Randy Garrison, \& Walter Archer. 2001. «Assessing teaching presence in a computer conferencing context». Journal of Asynchronous Learning Networks 5 (2).

Asterhan, Christa, \& Baruch Schwarz. 2010. «Online moderation of synchronous eargumentation.» International Journal of Computer-Supported Collaborative Learning 5 (3): 259-282. doi:10.1007/s11412-010-9088-2.

Aviv, Reuven, Zippy Erlich, Gilad Ravid, \& Aviva Geva. 2003. «Network analysis of knowledge construction in asynchronous learning networks». Journal of Asynchronous Learning Networks 7 (3): 1-13.

Bennett, W. Lance, Chris Wells, \& Allison Rank. 2008. «Young citizens and civic learning: Two paradigms of citizenship in the digital age». Seattle: Center for Communication \& Civic Engagement.

Bisquerra, Rafael. 1989. Métodos de la investigación educativa. Guía práctica. Barcelona (Spain): CEAC.

Brookfield, Stephen D., \& Stephen Preskill. 2005. «Discussion in a democratic society». In Discussion as a way of teaching: Tools and techniques for democratic classrooms, 2nd edition, 1-20. San Francisco, CA: Jossey-Bass.

Brubaker, Nathan D. 2012. «Negotiating authority through cultivating a classroom community of inquiry». Teaching and Teacher Education 28: 240-250. doi:10.1016/j.tate.2011.10.002.

Burnett, Cathy. 2003. «Learning to chat: Tutor participation in synchronous online chat». Teaching in Higher Education 8 (2): 247-261. doi:10.1080/ 1356251032000052474 . 
Cabero, Julio, Juan A. Morales, Rosalía Romero, Julio Barroso, Carlos Castaño, Jesús Salinas, Manuel Cebrián, et al. 2008. «E-learning: metaanálisis de investigaciones y resultados alcanzados». Programa de Estudios y Análisis. Seville (Spain): Secretaría de Estado de Universidades e Investigación, MEC.

Carr, Tony, Glenda Cox, Andrea Eden, \& Monique Hanslo. 2004. «From peripheral to full participation in a blended trade bargaining simulation». British Journal of Educational Psychology 35: 197-211.

Chou, C. Candace. 2002. «A comparative content analysis of student interaction in synchronous and asynchronous learning networks». In Proceedings of the 35th International Conference on System Sciences. Hawaii, HA. http://www.computer.org/csdl/proceedings/hicss/2002/1435/05/14350134b.pdf.

Daniels, Harry. 2012. «Institutional culture, social interaction and learning». Learning, Culture and Social Interaction 1: 2-11. doi:10.1016/j.lcsi.2012.02.001.

Garrison, D. Randy, \& Terry Anderson. 2003. E-learning in the 21st century: A framework of research and practice. London: Routledge Falmer.

Garrison, D. Randy, Martha Cleveland-Innes, \& Tak Fung. 2004. «Students' role adjustment in online communities of inquiry: Model and instrument validation». Journal of Asynchronous Learning Networks 8 (2): 61-74.

Garrison, D. Randy, Martha Cleveland-Innes, Marguerite Koole, \& James Kappelman. 2006. «Revisiting methodological issues in transcript analysis: Negotiated coding and reliability». The Internet and Higher Education 9: 1-8. doi:10.1016/j.iheduc.2005.11.001.

Garrison, D. Randy, \& Zehra Akyol. 2013. «Toward the development of a metacognition construct for communities of inquiry». Internet and Higher Education 17: 84-89. doi:10.1016/j.iheduc.2012.11.005.

Garrison, D. Randy, Terry Anderson, \& Walter Archer. 2000. «Critical inquiry in a text-based environment: Computer conferencing in higher education». Internet and Higher Education 11 (2): 1-14. doi:10.1016/S1096-7516(00)00016-6.

—. 2001. «Critical thinking, cognitive presence, and computer conferencing in distance education». The American Journal of Distance Education 15 (1): 7-23. . 2003. «A theory of critical inquiry in online distance education». In Handbook of distance education, edited by Terry Anderson \& Walter Archer, 113-127. Mahwah (NJ): Lawrence Erlbaum. 
Garrison, D. Randy, \& Walter Archer. 2000. A transactional perspective on teaching and learning: A framework for adult and higher education. Advances in learning and instruction series. Oxford (UK): Pergamon-European Association for Research and Learning.

Garrison, D. Randy, \& Myra Baynton. 1987. «Beyond independence in distance education: The concept of control». The American Journal of Distance Education 1(3): 3-15.

Garrison, D. Randy, Martha Cleveland-Innes, \& Tak Shing Fung. 2010. «Exploring causal relationships among teaching, cognitive and social presence: Student perceptions of the community of inquiry framework». The Internet and Higher Education 13 (1-2): 31-36. doi:10.1016/j.iheduc.2009.10.002.

Grossman, David L. 2008. «Democracia, educación para la ciudadanía e inclusión: Un enfoque multidimensional». Perspectivas 38 (1): 45-60.

Gunawardena, Charlotte N., Constance E. Lowe, \& Terry Anderson. 1997. «Analysis of a global online debate and the development of an interaction analysis model for examining social construction of knowledge in computer conferencing». Journal of Educational Computing Research 17 (4): 397-431.

Hrastinski, Stefan, Cristina Keller, \& Sven A. Carlsson. 2010. «Design exemplars for synchronous e-learning: A design theory a design theory approach». Computers \& Education 55 (2): 652-662 doi:10.1016/ j.compedu.2010.02.025.

Hrastinski, Stefan. 2008. «The potential of synchronous communication to enhance participation in online discussions: A case study of two e-learning courses». Information \& Management 45: 499-506.

Kanuka, Heather, Liam Rourke, \& Elaine Laflamme. 2007. «The influence of instructional methods on the quality of online discussion». British Journal of Educational Technology $38 \quad$ (2): 260-271. doi:10.1111/j.14678535.2006.00620.x.

Landis, J. Richard, \& Gary G. Koch. 1977. «The measurement of observer agreement for categorical data». Biometrics 33: 159-174.

Laurillard, Diana. 2002. «Teaching as mediating learning». In Rethinking university teaching: A conversational framework for the effective use of learning technologies, 2nd ed., 11-16. New York: Routledge. 
Mainkar, Avinash V. 2008. «A student-empowered system for measuring and weighing participation in class discussion». Journal of Management Education 32 (1): 2337. doi:10.1177/1052562906286912.

Manca, Stephania, Manuela Delfino, \& Elvis Mazzoni. 2008. «Coding procedures to analyse interaction patterns in educational web forums». Journal of Computer Assisted Learning 25: 189-200. doi:10.1111/j.1365-2729.2008.00296.x.

Mercer, Neil, \& Christine Howe. 2012. «Explaining the dialogic processes of teaching and learning: The value and potential of sociocultural theory». Learning, Culture and Social Interaction 1: 12-21. doi:10.1016/j.lcsi.2012.03.001.

Nagel, Lynette, \& Theuns G. Kotzé. 2010. «Supersizing e-learning: What a CoI survey reveals about teaching presence in a large online class». The Internet and Higher Education 13 (1-2): 45-51. doi:10.1016/j.iheduc.2009.12.001.

Oliveira, Isolina, Luis Tinoca, \& Alda Pereira. 2011. «Online group work patterns: How to promote a successful collaboration». Computer \& Education 57: 1348-1357. doi:10.1016/j.compedu.2011.01.017.

Park, Caroline L. 2009. «Replicating the use of a cognitive presence measurement tool». Journal of Interactive Online Learning 8 (2): 140-155.

Perera, Víctor H. 2007. «Estudio de la interacción didáctica en e-learning». Sevilla (Spain): Universidad de Sevilla. http://fondosdigitales.us.es/tesis/tesis/ 703/estudio-de-la-interaccion-didactica-en-e-learning/.

Remesal, Ana, \& Rosa Colomina. 2013. «Social presence and online collaborative small group work: A socioconstructivist account». Computers \& Education 60: 357367. doi:ht10.1016/j.compedu.2012.07.009.

Rotta, Mario, \& Maria Ranieri. 2005. E-tutor: Identità e competenze. I quaderne di form@are 4. Trento (Italy): Erickson.

Rourke, Liam, Terry Anderson, D. Randy Garrison, \& Walter Archer. 1999. «Assessing social presence in asynchronous text-based computer conferencing». The Journal of Distance Education 14 (2): 50-71.

Saba, Farahad. 2003. «Distance education theory, methodology and epistemology: A pragmatic paradigm». In Handbook of distance education, edited by Michael Grahame Moore \& William G. Anderson, 3-20. Mahwah (NJ): Lawrence Erlbaum.

Salmon, Gilly. 2000. E-moderating: The key to teaching and learning. 2nd ed. London: Kogan Page. 
—. 2004. «The five stage model». http://www.atimod.com/e-moderating/ 5stage.shtml.

Scardamalia, Marlene. 2002. «Collective cognitive responsibility for the advancement of knowledge». In Liberal education in a knowledge society, edited by Barry Smith, 76-98. Chicago: Open Court.

Stein, David S., Constance E. Wanstreet, Paula Slagle, Lynn A. Trinko, \& Michelle Lutz. 2013. «From "hello" to higher-order thinking: The effect of coaching and feedback on online chats». Internet and Higher Education 16: 78-84. doi:10.1016/j.iheduc.2012.03.001.

Stenbom, Stefan, Stefan Hrastinski, \& Martha Cleveland-Innes. 2012. «Student-student online coaching as a relationship of inquiry: An exploratory study from the coach perspective». Journal of Asynchronous Learning Networks. 16 (5): 37-48.

Tajfel, Henri. 1974. «Social identity and intergroup behaviour». Social Science Information 13 (2): 65-93. doi:10.1177/053901847401300204.

Traphagan, Tomoko W., Yueh-hui Vanessa C., Hyeseung Maria C., Benjaporn Wattanawaha, Haekyung Lee, Michael C. Mayrath, Jeongwon Woo, Hyo-Jin Yoon, Min Jung Jee, \& Paul E. Resta. 2010. «Cognitive, social and teaching presence in a virtual world and a text chat». Computers \& Education 55 (3): 923-936. doi:10.1016/j.compedu.2010.04.003

Weinberger, Armin, Karsten Stegmann, \& Frank Fischer. 2007. «Knowledge convergence in collaborative learning: concepts and assessment». Learning and Instruction 17 (4): 416-426. doi:10.1016/j.learninstruc.2007.03.007. 